\title{
A Study on the Needs for Guidelines on Part-And- Whole-Based Training for Volleyball Smash Basic Technique
}

\author{
Danang Wicaksono ${ }^{1}$, Furqon Hidayatullah ${ }^{2}$, Agus Kristiyanto ${ }^{3}$, Sapta Kunta Purnama ${ }^{4}$ \\ \{danang_wicaksono@student.uns.ac.id ${ }^{1}$, furqon@fkip.uns.ac.id ${ }^{2}$, aguskriss@yahoo.co.id ${ }^{3}$ \} \\ Universitas Sebelas Maret Surakarta, Surakarta, Indonesia ${ }^{1,2,3,4}$
}

\begin{abstract}
This study aims to identify coaches' needs for guidelines on training volleyball spike basic techniques, combining both part and whole training methods. Data in this descriptive study were collected using questionnaires filled out by 39 volleyball coaches in Special Region of. Data were then analyzed using quantitative descriptive method reported in percentage. Results indicated that coaches (100\%) agreed that a combination of part and whole trainings was effective and capable of maximizing the quality of volleyball spike basic techniques. $40 \%$ of the respondents claimed highly necessary while to the other $60 \%$, guidebooks to volleyball spike basic technique combining part and whole training methods were necessary. In regard to availability of instrument for assessing performance on volleyball spike technique, $63 \%$ of the coaches claimed that practical instrument for assessing spike technique performance of beginner volleyball athletes remained absent in sensor systems because the sensors used in UDM devices use laser sensors.
\end{abstract}

Keywords: Spike, Volleyball, Part Training, Whole Training

\section{Introduction}

Volleyball game is part of net sports in which players are obliged to hit the ball over the net to the opponent's area, making sure the opponent fails to return the ball over the net [5]. The main goal of net games is to score more points by hitting more balls/objects than the opponent does [6]. Volleyball is a relatively tough game requiring complex techniques ranging from basic to advanced levels. To play this game, players should master proper basic techniques, requiring them to follow some special tips. The patterns of techniques in volleyball are relatively sequential and repetitive. The series of volleyball cycles can be seen in the following figure: 


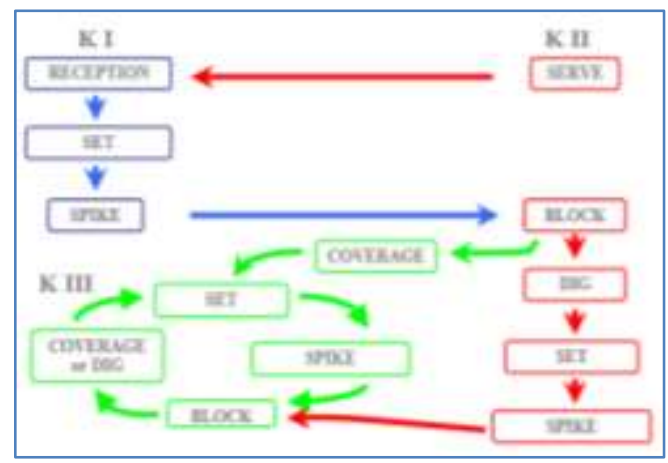

Fig. 1. The structure or cycle in volleyball game [9]

Techniques in volleyball were developed based on practices, aiming at finding solutions to problems in certain motions in most economic and useful manners [1]. Basic techniques should be taught and trained as effectively as possible due to the fact that mastery of basic techniques is the main element that influences development of techniques in more advanced level. At this stage, coaches should put forward process approach that is to develop basic techniques in volleyball games as well as possible. Coaches should thoroughly find the flaws of each technique performed by the athletes. They should also be able to provide the athletes with feedback and revisions to each mistake. Mistakes made by beginner athletes should be corrected immediately to prevent them from adopting the wrong techniques. Automation of basic techniques in volleyball game takes time; therefore, control and roles of the coaches should be central in addition to proper selection of training models. In volleyball, athletes' ability to master required kinesthetic skills constitutes an achievement. In each sport, one of fundamentals of success lies on the ability to perceive and understand movement pattern accuracy in its activity [7]. Fundamental rules in basic learning [2] includes, such as:

a. The law of excellence: learn the right techniques first, avoid repeating false attempts.

b. The law of sports: one will need to acquire motor skill to be fully automated. Automation is a result of exceptional repetition.

Fitts and Postner proposed three stages of motor skill acquisition that include: cognitive, fixation (associative), and autonomous stages [10]. Meanwhile, other expert, Merril (1976), identified stages in motor skill acquisition as motor mastery, refinement and stabilization or sport technique skill.

In volleyball, spike is one of techniques that incorporates considerably complex movements. This technique requires high-level movement coordination of all extremities (superior, inferior and truncus) and coordination between body movements and other objects (ball). Teaching beginner volleyball athletes basic spike techniques requires special methods. To ensure training being effective and efficient, selection of training methods to acquire new movements must be done accurately. Two methods to train movement skills include part and whole training. Whole training is one type of training in which all techniques are practiced as a whole. In part training, on the other hand, athletes practice each technique or group of techniques apart. Both methods can be combined by practicing the techniques or skills separately, 
followed by combining all the parts together in a whole-training [8]. Cristina \& Corcos stated that to acquire complex skills that involve a range of body parts or movements in one technique simultaneously, one can break the task to be learned down into parts [12].

Part-training method can be broken down into three parts including segmentation, fractionation, and simplification [4]. There are two keywords to break techniques down into some parts [8], including: a) The low degree of interdependence of the tasks; b) The high complexity of the tasks;

Goldstein highlighted the importance of analyzing tasks to determine whether a task can be split into coherent parts [3] as follows: a) Progressive part, in which the first two parts of the task are practiced separately before being practiced together. The third part is practiced in isolation and then added to the first two parts and so on, for example $\mathrm{A}, \mathrm{B}, \mathrm{A}+\mathrm{B}, \mathrm{C}, \mathrm{A}+\mathrm{B}+$ $\mathrm{C}$; b.) Repetitive part, often known as cumulative part, in which the first part of the task is practiced separately before adding the second and the subsequent parts, for example $\mathrm{A}, \mathrm{A}+\mathrm{B}$, $\mathrm{A}+\mathrm{B}+\mathrm{C}$; C) Isolated part, in which some parts of the task are practiced separately before practicing the whole task, for example A, C, E, A+B+C+D+E. d) Retrogressive part, in which the last part of the task is practiced in isolation, followed by learning the last and the penultimate parts and continued until all parts are learned, for example $\mathrm{C}, \mathrm{B}, \mathrm{A}, \mathrm{A}+\mathrm{B}+\mathrm{C}$.

\section{Methods}

This was a descriptive study that adopted questionnaires for data collection purpose. Subjects of the study were 39 volleyball coaches in Special Region of Yogyakarta selected using incidental sampling technique. Data were then analyzed using quantitative descriptive method and reported in percentage.

\section{$3 \quad$ Results and discussion}

Before Survey results demonstrated coaches' awareness of the importance of spike as a predominant way to score a point in volleyball game. They understand how spike training should be adjusted to athletes' characteristics and how teaching beginner athletes differs from teaching intermediate and advanced level athletes. Training materials, in addition, should be modified to meet with athletes' levels to make sure their needs are fulfilled.

Beginner athletes are not miniature intermediate and advanced level athletes; therefore special training program should be prepared. Spike training materials for beginners should be made simpler. Coaches are aware of the fact that spike is one of the most strenuous techniques in volleyball game. This technique requires great coordination and therefore demands complex movements. Eyes, hands, and legs coordinate simultaneously to produce synchronized and efficient basic spiking techniques. A combination of timing for jumping off and hitting accuracy often adds to existing level of difficulties. This has pushed coaches to simplify materials to help beginner athletes learn spiking.

A combination of part and whole training methods can help address issues relating to spiking training process among beginners. Guidebooks to spiking that combines part and whole training methods should be made available for coaches, athletes and parents. Of all subjects, $60 \%$ coaches were informed of the availability of the books, which, however, did not specify the use of part-and-whole-training combination in spiking for beginners. On the one 
hand, $33 \%$ of respondents mentioned that spiking training guidebooks remained unavailable while, at the same time, the rest $7 \%$ of respondents were completely uninformed as can be seen in the following figure:

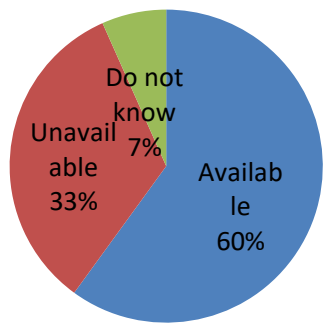

Fig. 2. Availability of guidebooks on spiking training for beginner athletes

The book content remained flawed as it failed to provide detailed information concerning what methods are accurate for teaching spiking to beginner athletes. According to the coaches, the existing books failed to explain how to teach basic spiking techniques to beginners using the simplest to the most complex methods. The books also lacked detailed examples of exercises to perform at each stage. In addition, systematic information concerning how to teach spiking techniques, either partly or wholly, remained absent.

Publication of a guidebook to basic spiking techniques for beginner athletes using a combination of part and whole trainings can help address the above-mentioned issues. Survey results have given urgency to this guidebook issue. Data suggested that $60 \%$ coaches needed the guidebook while the rest $40 \%$ really needed one.

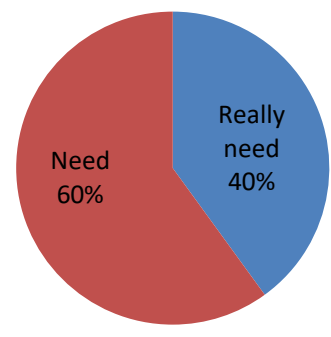

Fig. 3. The needs for a guidebook to basic spiking techniques for beginner athletes using a combination of part and whole trainings.

This training method can help to simplify spiking practices among beginner athletes. Training starts from the simplest or easiest then levels up on such gradual basis that athletes do not feel overwhelmed. When each stage is passed systematically, spiking techniques will be simpler while success rate (of the process) will be higher. Part training method provides coaches with ease in training spike basic techniques to beginner athletes. The part method leads to the whole spiking. The part spiking movements will eventually be combined as a whole via intact practice. All coaches (100\%) believed that combining part and whole meth- 
ods in training is highly effective and is able to maximize the quality of spiking techniques at each level (preparation, execution, landing).

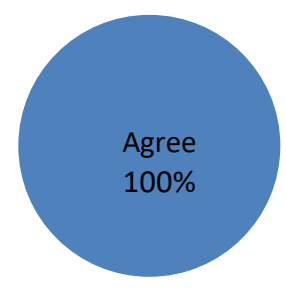

Fig. 4. Assessment resulting in the fact that part and whole training methods are effective and able to maximize quality of spiking techniques.

The whole technique is practiced to combine parts or phases in spiking, from preparation, execution, to landing, together. Coaches argued that the whole method is effective for teaching athletes who have mastered parts of the techniques (preparation, execution, landing.

Performance on practicing a technique should be evaluated constantly. Coaches have been informed of the existence of instruments to evaluate the quality of basic spiking techniques among beginner athletes. They, however, have not adopted the instruments comprehensively. Instead, they took only certain points they thought crucial for observing performance on training basic spiking techniques. Coaches, for example, observed contact made while hitting: can a player hit at his higher jump? Coaches observed the final step and arm swing while jumping off the ground. According to the survey, $63 \%$ of coaches remained clueless about instruments to assess the quality of basic spiking techniques among beginner athletes. They have not made in-depth use of existing instruments and therefore need simple and practical instruments to evaluate results of spiking training among beginner athletes.

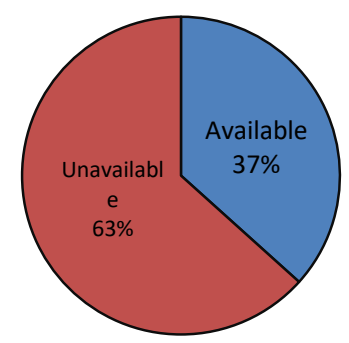

Fig. 5. Evaluation of availability of practical instrument for assessing performance on volleyball spike technique among beginners.

\section{Conclusion}

Teaching spiking techniques to beginner athletes requires special training method due to complexity of spike movements. A combination of part and whole trainings is one of the solu- 
tions. To all coaches $(100 \%)$, this combination is effective and capable of maximizing the quality of volleyball spike basic techniques in each phrase: preparation, execution, and landing. A part-and-whole combination in spiking training must be done systematically; therefore, there has been a need for a systematic guidebook among volleyball coaches. Of all subjects, $60 \%$ were informed of the availability of the training guidebooks, which, however, failed to specify the use of part and whole training combination. On the one hand, 33\% subjects argued that guidebooks to spiking remained unavailable while the rest $7 \%$ remained uninformed. This has added urgency to supply of guidebooks to spiking technique training that adopts part and whole training methods specifically and systematically. Data suggested that to $40 \%$ coaches, guidebooks are necessary while to $60 \%$ of them the books are highly needed. In addition, to provide positive feedback, training method and process must be supported with instruments to assess performance. This instrument must be simple, convenient, efficient, or, in other words, practical. Data suggested that $63 \%$ volleyball coaches needed a practical instrument to assess spiking performance of beginner athletes

\section{References}

[1] Beutelstahl Dieter.1984. Belajar dan Berlatih Sambil Bermain Vollyball. Pioner Jaya. Bandung.

[2] Bompa TO \& Claro, F. 2009. Periodization in Rugby. Maidenhead: Meyer \& Meyer Sport (UK) Ltd

[3] Buckler R \& Caple J. 2004. The Theory and Practice of Training Rev. 5th ed. India: Replika Press

[4] Gopher, D. Weil, M., \& Siegel, D. (1989). Practice under changing priorities: An approach to the training of complex skills. Acta Psychologica, 71, 147-177.

[5] Grifin JJ. (1997). Teaching sport concepts and skill: a tactical game approach. Champaign, IL: Human kinetics.

[6] Hopper T. 1998. Teaching games centred games using progressive principles of play. Canadian Association for Health, Physical Education, Recreation and Dance Journal, 64 (3), 4-7. http://jonathan. mueller. faculty. noctrl.edu/ toolbox/whatisit. htm\#looklike. http://www. Best volley balldrills. com/ http://www.jssm.org

[7] Kenny Bonnie \& Gregory, Cindy. 2006. Volleyball step to success: sport instruction series. USA: Human Kinetics.

[8] Martens R 2012. Successful coaching. 4th ed. Human Kinetics United States.

[9] Palao JM, Santos JA \& Urena A. 2004. Effect of team level on skill performance in volleyball. International Journal of Performance Analysis in Sport, 4 (2), 50-60.

[10] Schmidt AR. 1988. Motor Control and Learning. Second Edition. Illinois: Human Kineticks Publisher Inc. 